\title{
COMPARISON OF GROWTH AND YIELD PERFORMANCE OF (UC-82B \& LOCAL) VARIETIES OF TOMATOES (Lycopersicum esculentum Mill.) BY GRAFTING, MUTATION AND SEASONAL VARIATIONS
}

\author{
Aminu Y. ${ }^{1}$, Bichi B. S. ${ }^{1}$, R. M. Kutama ${ }^{2}$ and Yassar Z. R. ${ }^{1}$ \\ ${ }^{1}$ Biology Department, College of Education and Preliminary Studies, Kano State2. \\ ${ }^{2}$ Biology Department, Sa`adatu Rimi College of Education, Kumbotso Campus, Kano State \\ *Corresponding Author: Email: aminuyahayafagge@gmail.com GSM: +2347035347997
}

\section{Cite this article:}

Aminu Y., Bichi B.S., R.M. Kutama, Yassar Z.R. (2021), Comparison of Growth and Yield Performance of (UC82B \& Local) Varieties of Tomatoes (Lycopersicum esculentum Mill.) by Grafting, Mutation and Seasonal

Variations. African Journal of Biology and Medical Research 4(3), 92-98. DOI: 10.52589/AJBMRYCISGQS0.

\section{Manuscript History \\ Received: 9 Feb 2021 \\ Accepted: 5 March 2021}

Published: 9 Aug 2021

Copyright $\left({ }^{\circ} 2020\right.$ The Author(s). This is an Open Access article distributed under the terms of Creative Commons AttributionNonCommercial-NoDerivatives 4.0 International (CC BY-NC-ND 4.0 ), which permits anyone to share, use, reproduce and redistribute in any medium, provided the original author and source are credited.
ABSTRACT: The Comparison of Growth and Yield Performance of (UC-82B \& Local) Varieties of Tomatoes (Lycopersicum esculentum Mill.) by Grafting, Mutation and Seasonal Variations was investigated with the aim of inducing variability that could be exploited in the improvement of some quality traits in Tomato plants. The seeds of two varieties of tomato: UC-82B and Local varieties were treated at three different concentrations of sodium azide (1.0mM, $1.5 \mathrm{mM}, 2.0$ $\mathrm{mM}$ and $0.0 \mathrm{mM}$ as control). The results obtained revealed highly significant difference $(P \leq 0.01)$ in the effects of sodium azide on survival rates, number of fruits, and fruit weight. Similarly, highly significant differences $(P \leq 0.01)$ was found between the treatments in Survival rate, except on the number of fruits and fruit weight, where no significant differences exist. More so, significant differences were found in the traits between the seasons except in fruit number. The result shows that 1.0 $m M$ concentration of Sodium Azide and grafting improves some important quality traits of tomato that could be utilized for further improvement of tomato crop. However, the response of variety UC to grafting was higher. Highly significant difference $(P \leq 0.01)$ was found among the seasons in terms of fruit weight, and significant difference $(P \leq 0.05)$ was found among the seasons on survival rate, while no significant difference was found among the seasons in terms of fruits number. More so, highly significant difference $(P \leq 0.01)$ was found in the interaction of varieties with seasons on Survival rate and number of fruit tomato varieties except on fruit weight, where no significant difference was found.

KEYWORDS: Grafting, Mutation, Season, Variation, UC, $82 B$, Local variety. 


\section{INTRODUCTION}

Tomato (Lycopersicon esculentum Mill.) constitutes one of the most valuable horticultural crops, not only because of its economic importance, but also for its sensory qualities and nutritional value. It is consumed in the form of fresh as well as processed products. More than $80 \%$ of tomatoes grown throughout the world are processed into products such as sauce, juice, ketchup, canned tomato, stew and soup (Viskelis P., Radzevicius A., Urbonaviciene D., Viskelis J., Karkleliene R., Bobinas C., 2015). Epidemiological studies have proved the importance of tomato and its products in reducing various ailments because they contain high amounts of antioxidants such as carotenoids, polyphenols, ascorbic acid and many others (Perveen R., Suleria H.A., Anjum F.M., Butt M.S., Pasha I.,Ahmad S., 2015). Lycopene is the most plentiful carotene in the tomato fruit, comprising up to $90 \%$ of the total carotenoids present (Viskelis et al., 2015), and is the most important antioxidant with a high oxygen free radical-scavenging and quenching capacity, and thus provides protection against chronic diseases, such as several types of cancer, including cancer in the mouth, pharynx, esophagus, stomach and large intestine, and cardiovascular diseases (Perveen et al., 2015).

Lycopene is also the pigment mainly responsible for the red colour of tomato fruits. Various studies have reported that the lycopene content in tomatoes is most notably influenced by various genetic and environmental factors, such as the cultivar, growing season, cultivation conditions and harvesting stage (Toor et al., 2006; Rickman Pieper and Barrett, 2008).

Successful production of processing tomato requires to increase both yield and fruit quality. There has been a substantial research effort devoted to the processing tomato; however, it is not clear how the environment, cropping techniques and crop management affect each of the fruit characteristics measured at harvest to estimate the quality of processed products. In addition, during the last decades, the demand for organically grown products has increased because many people are concerned about the environment and believe that organic products are healthier than the conventional ones (Riahi A., Hdider C., Sanaa M., Tarchoun N., Kheder M.B., Guezal I., 2009). This study aimed to investigate and determine the effects of sodium azide, Grafting and Seasonal Variations on Some Growth Parameters on Two Varieties of Tomato (Solanum lycopersicum).

\section{Materials and Method}

The research was conducted in the Botanical Garden of the Department of Biological Sciences, Ahmadu Bello University, Zaria. (Lat $11^{0} 12^{1} \mathrm{~N}$, Long $7^{0}, 37^{1} \mathrm{E}$, Alt $550-700 \mathrm{~m}$ above sea level) (Anonymous, (2014).

\section{Sources of the Seeds}

Seeds of two varieties of cultivated tomato (UC-82B and a local variety) were collected from the Institute for Agricultural Research (I.A.R), Ahmadu Bello University Zaria, Nigeria.

\section{Treatment and Experimental Design}

The treatments used in the research are Grafting and mutation, three concentrations of Sodium Azide and three varieties of tomatoes (Roma, UC82B and a local variety) with three different concentrations of sodium azide $(0.1 \mathrm{mM}, 1.0 \mathrm{mM}, 2.0 \mathrm{Mm})$. These were laid out in a Completely Randomized Design (CRD) with three replications. The seeds of the three tomato 
varieties were soaked//treated with three different concentrations of Sodium Azide $(0.1 \mathrm{mM}$, $1.0 \mathrm{mM}, 2.0 \mathrm{Mm}$ ) for 4 hours while $0.0 \mathrm{mM}$ as control. The seeds used for rootstocks were planted 2 days prior to that of the shoots. Tongue grafting approach was used. This is due to the relative advantage of the method over others such as its being used on larger plants, three times faster than other techniques, high success rate and is easy to handle.

After two weeks of planting, and a day prior to grafting, the plants used for grafting were watered fully to make them turgid. One-fourth of the plants used for rootstock were cut at slant early in the morning. The shoots were also cut in the same way. The two cut ends were placed in direct contact and use a small clip was used to hold the cut surfaces together. This was repeated in the $3^{\text {rd }}$ and $4^{\text {th }}$ week of planting, while the remainders were left as control as described in McVoy (2005) protocol.

\section{Data Collection}

Data were observed and collected on number of Survival rate, number of fruits/plant, and fruit weight.

\section{Survival Rate $(\%)$}

The number of grafts that survive during the emergence of first flower were determined and their percentages taken and recorded. Leafless grafts were considered as dead.

\section{Number of Fruits/Plant}

The number of fruits produced per plant was determined through counting per treatment for each variety after twelve weeks of planting and recorded.

\section{Dry Weights of the Fruits (g)}

The weights of 100 fruits dried in the oven at $90{ }^{\circ} \mathrm{C}$ for 48 hours were determined in grams using a balance and recorded. (Mettier, PS15. Max-15000g).

\section{Data Analysis}

All the data collected were analyzed using Analysis of Variance, and the means were separated using Duncan's Multiple Range Test, (DMRT).

\section{RESULTS}

The results from the combined analysis of variance on the effects of mutation and grafting on some selected traits of three tomato varieties are presented in the table below. The results showed highly significant difference $(\mathrm{P} \leq 0.01)$ in the effect of concentrations of sodium azide on all the selected traits of the two varieties of Tomato. Similarly, high significant difference $(\mathrm{P} \leq 0.01)$ was found among the varieties in terms of all the selected traits. However, no significant difference was found in the effect of the treatments on fruits number and fruit weight, except on survival rate where the effect is significant $(\mathrm{P} \leq 0.05)$. Highly significant difference $(\mathrm{P} \leq 0.01)$ was found among the seasons in terms of fruit weight, and significant difference $(\mathrm{P} \leq 0.05)$ was found among the seasons on survival rate, while no significant difference was found among the seasons in terms of fruits number. 
However, no significant difference in the interactions of sodium Azide with varieties and between sodium azide with the treatments on all the selected traits of the two tomato varieties. Similarly, no significant difference was found in the interactions of sodium azide with seasons in almost all the selected traits. However, highly significant difference $(\mathrm{P} \leq 0.01)$ was found in the interaction of varieties with treatments on fruit number and fruit weight, while no significant difference was found in the interaction of varieties with treatments on the other remaining selected trait. More so, highly significant difference $(P \leq 0.01)$ was found in the interaction of varieties with seasons on Survival rate and number of fruit tomato varieties except on fruit weight, where no significant difference was found.

Furthermore, highly significant difference $(\mathrm{P} \leq 0.01)$ was found in the interaction of the treatments with seasons on the fruit weight except on fruit number; where the interaction is significant $(\mathrm{P} \leq 0.05)$ and on survival rates, where no significant difference was found in the interaction. However, no significant difference was found in the interaction of sodium azide concentrations with varieties and treatments and interaction of sodium azide with varieties and seasons on the selected traits of the tree tomato cultivars.

\section{Combined Effects of Grafting and Sodium Azide Interactions on Some Growth Parameters on Three Varieties of Tomato in Two Different Seasons}

\begin{tabular}{|c|c|c|c|c|}
\hline Sources of Variation & $\mathbf{d F}$ & $\begin{array}{l}\text { Survival } \\
\text { Rate }(\%)\end{array}$ & $\begin{array}{l}\text { Number } \\
\text { of Fruits }\end{array}$ & Fruit Weight (g) \\
\hline Replication & 2 & $74.54^{\mathrm{ns}}$ & $11.87 *$ & $55.92 * *$ \\
\hline Concentration & 3 & $14265^{* *}$ & $188.59 * *$ & $383 * *$ \\
\hline Variety & 2 & $3803.53 * *$ & $37.26 * *$ & $564.34 * *$ \\
\hline Treatments & 2 & $878.43 *$ & $5.26^{\mathrm{ns}}$ & $21.68^{\mathrm{ns}}$ \\
\hline Seasons & 1 & $874.67 *$ & $0.01^{\mathrm{ns}}$ & $189.84 * *$ \\
\hline Conc. $x$ Trt. & 6 & $72.30^{\mathrm{ns}}$ & $1.36^{\mathrm{ns}}$ & $6.23^{\text {ns }}$ \\
\hline Conc. $x$ Var. & 6 & $44.73^{\mathrm{ns}}$ & $3.19^{\text {ns }}$ & $14.17^{\mathrm{ns}}$ \\
\hline Conc. $x$ Seas & 3 & $35.35^{\mathrm{ns}}$ & $0.91^{\mathrm{ns}}$ & $9.67^{\mathrm{ns}}$ \\
\hline Var. $x$ Trt. & 4 & $164.47^{\mathrm{ns}}$ & $14.79^{\mathrm{xx}}$ & $70.64^{\mathrm{xx}}$ \\
\hline Var. $x$ Seas. & 2 & $4860.2^{\mathrm{xx}}$ & $95.36^{\mathrm{xx}}$ & $12.12^{\mathrm{ns}}$ \\
\hline Trt. x Seas. & 2 & $138.49^{\mathrm{ns}}$ & $12.22^{\mathrm{x}}$ & $45.54^{\mathrm{xx}}$ \\
\hline Conc. $x$ Var. $x$ Trt. $x$ Seas. & 18 & $153.02^{\mathrm{ns}}$ & $2.82^{\mathrm{ns}}$ & $1.63^{\text {ns }}$ \\
\hline Error & 142 & 148.56 & 2.78 & 7.53 \\
\hline
\end{tabular}

\section{DISCUSSION}

The differences observed in most of the quantitative and qualitative traits among the sodium azide induced mutants of tomato evaluated showed significant improvements in the selected traits.In the present investigation, survival percentage decreased with increasing concentration of sodium azide. This finding conformed to the earlier report by (Ahloowalia \& Maluszynski 2001) that, the viable mutants observed are mainly dependable measure of genetic effect in mutagen. The increased number of fruits per plant due to sodium azide treatments was also in conformity with the work of (Adamu \& Aliyu 2007) who reported 
increased in growth and yield parameters of tomato due to sodium azide treatments. There was a reductions in the survival percentages with increasing concentrations for both chemicals in the $\mathrm{C}_{1}$ generation. Reductions in survival percentages due to the effects of mutagens on various crop plants have earlier been documented by (Mensah \& Akomeah1997) and (Mensah et al. 2005).

More so, the improvement in the growth and yield components of tomato due to sodium azide treatments stressed the effect of mutation on the growth and yield of plants. This is in agreement with the work of (Adamu et al. 2002) who observed when groundnut was treated with gamma rays and (Sheeba et al. 2005) who reported the effect of gamma rays and EMS were used to treat Sesanum indicum L. where survival was reduced significantly with an increase in dosage levels of both mutagens. However, in contrast, (Sasi et: al. 2005) showed that all plant mutant types registered lower yields compared to their parents in the study of the effects of diethylsulphate and EMS on Okra (Abelmoschus esculentum (L.) var. MDU-1). The increased in fruit quality (such fruit weight and number of fruits) due to induced mutagenesis by sodium azide signifies the vital role played by the mutagen in improving the quality traits of tomato.

The distinct differences observed in most of the qualitative traits among the grafted tomato plants compared to the controls showed improvements in fruits quality induced by grafting. The improved fruit characteristics of tomato due to grafting is in agreement with the findings of (Lee, 1994) and (Pogonyi et., al 2005), who independently reported improvements in fruits quality due to grafting. The increase in the number of fruits among the grafted tomatoes was consistent with the work of (Ibrahim et: al. 2001) who found that the total number of fruits per plant in non- grafted plants was statistically different from those of grafted plants.

In a similar study by (Khah et: al. 2006) fruit weight of grafted plants was found to be higher than in non-grafted plants. In the present study, the number of fruits and fruit weights of non grafted plants were significantly lower than the corresponding values for plants grafted onto both rootstock cultivars.

Higher fruit yield parameters found in this study could be due to the fact that grafting combines novel traits of the two grafted plants after grafting operation. This has also been reported by (Tsouvaltzis et al. 2004).

The fruit characteristics of grafted plants were compared with those of non-grafted plants. The results showed that the fruit index (number of fruits and fruit weight) were significantly influenced by grafting. The results agree with those reported by (Lee, 1994) who concluded that fruit shapes are influenced by rootstocks. (Pogonyi et al. 2005) reported that when Lemance $F_{1}$ was grafted onto Beaufort rootstock, increased yield was caused mainly by higher average fruit weight. (Ibrahim et al. 2014) also found that the total number of fruits in non-grafted plants was statistically different from the total for grafted plants. In grafted combinations, the total fruit yield per plant increased significantly in comparison with that of the control plants. (Ibrahim et al. 2001) observed similar results in grafted and non-grafted tomato plants. 


\section{CONCLUSION}

The effect of grafting, mutation and seasons was found to be beneficial in improving certain qualitative traits of tomato varieties. The use of grafting in crop improvement helps to understand the mechanism of grafting induction and to quantify the frequency as well as the pattern of changes in different selected plants by grafting. Variety UC is therefore recommended for processing industries. More so, Induced mutation using various concentrations of sodium azide and grafting technique were employed singly and in combination on the three varieties of tomato with the aim of improving the growth and yield parameters of the plants in both the wet and dry seasons. It was concluded that, sodium Azide via mutation improves some important quality traits of tomato that are of high economic value and possible recommendations made.

\section{REFERENCES}

Adamu, A. K., and Aliyu, H.( 2007). "Morphological Effects of Sodium Azide on Tomato (Lycopersicon esculentum Mill)." Science World Journal 2 (4): 9-12.

Adamu, A. K., Clung, S. S. \& Abubakar, S. 2004. Effects of Ionizing Radiation (GammaRays) on Tomato (Lycopersicon esculentum L.). Nigeria Journal of Experimental and Applied Biology, 5 (2): 185-193.

Adamu, A. K., Oluranju, P. E., Bate, J. A. \& Ogunlade, O. T.2002. Radiosensitivity and Effective Dose Determination in Groundnut (Arachis hypogaea L.) Irradiated with Gamma-Rays. Journal of Agriculture and Environment, 3(1): 17-84. and Benefits. J.. Hort. Science 29:235-239.

Anonymous (2009) Grafting http://www.ars.usda.gov.Retrieved July 10, 2010

Dhaliwal, M.S., Kaur, A., and Singh, S. (2002) Genetic Analysis and Correlations Involving Populations Derived from L. esculentum x L. pimpinellifolium Crosses of Tomato. $J$. Genet. and Breed. 56:345-352.

Dorais, M., Papadopoulus, A., and Gosselin, A. (2001): Greenhouse Tomato Fruit Quality. Horticultural Review 26, 239-319.

EL-Kaaby, E. A., EL-Anny, J. A., AL-Qaisy, S. A.,AL-Ajeely, A. N., Ebraheem, H. A., Saleh, K. S., andALaubaidy, A. A.( 2012). "Effect of Salinity Stress OnCallus Induction and Plant Regeneration of Three TomatoHybrids Solanum lycopersicum Mill. In Vitro." Journal of University of Duhok 15 (1): 457-461.

Encarta 2005. Microsoft Encarta encyclopedia Microsoft CD Rom

Gill A.S (1992): Taxonomy of Flowering Plants. Africana PEP Publishers, Ibadan.

Gruda, N. (2009) Do Soilless Culture Systems have an Influence on Product quality of vegetables? Journal of Applied Botany and Food Quality 82: 141-147

Haq, I., Memon, S., Parveen, N. G., and Muhammad, TR. (2011). "Regeneration of Plantlets under NaCl Stressfrom NaN3 Treated Sugarcane Explants.” Afr. J. Biotechnol 10 (72): $16152-16156$.

Ibrahim M., Munira, M.K., Kabir, M.S., Islam, A.K.M.S., and Miah, M.M.U. (2001): Seed Germination and Graft Compatibility of Wild Solanum as Rootstock of Tomato. Asian Journal of Biological Sciences, 1: 701-703.

Johnson S.I. (2005): Economic Botany for Degree Students: Dorayi Babba Commercial Press Nig Ltd Kano pp $175-179$. 
Khah, E.M., Kakava, E., Mavromatis, A., Chachalis, D., and Goulas, C. (2006): Effect of Grafting on Growth and Yield of Tomato (Lycopersicon esculentum Mill.) in Green House and Open-Field. Journal of Applied Horticulture 8:3-7.

Lee, J.M. (1994) Cultivation of Grafted Vegetables I. Current Status, Grafting Methods,

Mann A., Gbate M., and A.N. Umar (2003): Medicinal and Economic Plants of Nupe land. Jubeevans books and publications, Bida, Niger state.

McVoy, R. (2005): Grafting Techniques for Green House Tomatoes. A Paper Presented at the Green House Tomato Conference, NESARE and UMass Extension, Nov. 10, 2005.

Mensah, J.K., Akomeah, P.A.,and Ekpekurede, E.O.(2005): Gamma Irradiation Induced Variation of Yield Parameters in Cowpea (Vigna unguiculata (L.) Walp.) Global Journal of Pure and Applied Sciences 11(3): 327-330.

Perveen R., Suleria H.A., Anjum F.M., Butt M.S., Pasha I.,Ahmad S., 2015.Tomato (Solanum lycopersicum) carotenoids and lycopenes chemistry; metabolism, absorption, nutrition, and allied health claims A comprehensive review. Crit. Rev. Food Sci. Nutr. 55(7), 919-929.

Pogonyi, A., Pek, Z., Helyes, L., and Lugasi, A. (2005): Grafting Tomatoes for Early Forcing in Spring has a Major Impact on the Overall Quality of main Fruit Components. ActaAlimentaria 34:453-462

Riahi A., Hdider C., Sanaa M., Tarchoun N., Kheder M.B., Guezal I., 2009. Effect of conventional and organic productions systems on the yield and quality of field tomato cultivars grown in Tunisia. J. Sci. Food Agric. 89, 2275-2282.

Sheeba, A., Abumalarmalhi, J., Babu, S.,and Ibrahim, S. N.M. (2005): Mutagenic Effects of Gamma-Rays and EMS in $\mathrm{M}_{1}$ generation in Sesame. Resources on Crops 6(2): 300306.

Toor R.K., Savage G.P., Heeb A., 2006. Influence of different types of fertilizers on the major antioxidant components of tomatoes. J. Food Compos. Anal. 19, 20-27.

Viskelis P., Radzevicius A., Urbonaviciene D., Viskelis J., Karkleliene R., Bobinas C., 2015. Biochemical parameters in tomato fruits from different cultivars as functional foods for agricultural, industrial, and pharmaceutical uses. In: Plants for the future. H. El- Shemy (Ed.), InTech Open, doi: 10.5772/60873. 